\title{
DIE GEGENSTÄNDE DER FAMILIENMEDIATION ANLÄSSLICH DER SCHEIDUNG IM TÜRKISCHEN RECHT
}

DOI: https://doi.org/10.33717/deuhfd.897886

\section{Dr. Ö̆rr. Üyesi Merve ÜREM ÇETINEL*}

\section{MATTERS APPROPRIATE FOR FAMILY MEDIATION IN THE DIVORCE PROCESS UNDER TURKISH LAW}

\begin{abstract}
As a legal institution, mediation has been regulated in a specific and detailed way with the Law on Mediation in Civil Disputes numbered 6325 and dated 07/06/2012. According to Art. 2 (B) of this Law, mediation is defined as the method used for the resolution of disputes, employing systematic techniques, carried out voluntarily and with the participation of an impartial and independent third person with specialty training, bringing the parties together to discuss and negotiate, and establishing a communication process between the parties in order to help them to understand each other and thus enabling them to work out their own solutions. The resolution of disputes with the help of an impartial and independent third person, as referred to in the definition provided in the Law, plays a significant role also in the field of family law.

The possibility of resolving disputes arising from family law under the management of an impartial and competent person other than the judge represents a new and current phenomenon in Turkish law. Since that the Law on Mediation in Civil Disputes includes deficient and general provisions, it is important to identify which matters will be mediatable in terms of family mediation. This is because mediatable matters in connection with both mediations, in general and of family mediation are not exhaustively enumerated in the Law. Pursuant to Art. 1/II sent. 1 of the Law, family mediation could be applied only for the matters that spouses can freely dispose of. Nonetheless, there is no consensus in the legal literature on the question of which numerus clausus family law disputes are appropriate for family mediation according to this provision. Therefore, our paper aims to evaluate the subject matter and the scope of family mediation in Turkish law, and particularly the function of family

Dr.iur. an der Rechtswissenschaflichen Fakultät der Universität Istanbul Medeniyet (e-posta: mrvurem@yahoo.com) ORCID: https://orcid.org/0000-0002-4710-6545 (Makalenin Geliş Tarihi: 30.04.2020) (Makale Gönderilme Tarihi: 05.05.2020/ Makale Kabul Tarihi: 10.09 .2020$)$
\end{abstract}


mediation in the divorce process in the light of the Law on Mediation in Civil Disputes.

\section{Keywords}

Alternative dispute resolution methods, Mediation, Family mediation, suitability for mediation, Divorce

\section{TÜRK HUKUKUNDA BOŞANMA SÜRECINDE AILE ARABULUCULUĞUNA ELVERISTLİ KONULAR}

\section{$\ddot{\mathbf{O z}}$}

Hukuki bir kurum olarak arabuluculuk, 07/06/2012 tarihli 6325 sayll Hukuk Uyuşmazlıklarında Arabuluculuk Kanunu ile özel ve ayrıntılı bir şekilde düzenlenmiştir. Alternatif uyuşmazlık çözüm yöntemlerinden biri olan arabuluculuk Hukuk Uyuşmazlıklarında Arabuluculuk Kanunu m. 2/b. b'de "sistematik teknikler uygulayarak, görüşmek ve müzakerelerde bulunmak amacıla tarafları bir araya getiren, onların birbirlerini anlamalarını ve bu suretle çözümlerini kendilerinin üretmesini sağlamak için aralarında iletişim sürecinin kurulmasını gerçekleştiren, tarafların çözüm üretemediklerinin ortaya çıkması hâlinde çözüm önerisi de getirebilen, uzmanlık eğitimi almış olan tarafsız ve bă̆ımsız bir üçüncü kişinin katılımıyla ve ihtiyarî olarak yürütülen uyuşmazlık çözüm yöntemi" olarak tanımlanmıştır. Tarafsız bir kişinin yardımı ile uyuşmazlı̆̆ın çözümü, aile hukukundan kaynaklarından uyuşmazlıklarda da önemli bir rol oynamaktadır.

Hâkim dışında, tarafsız ve uzman kişi yönetiminde aile hukukundan kaynaklı uyuşmazlıkların çözülmesi imkânı Türk hukukunda yeni ve güncel bir gelişmedir. Hukuk Uyuşmazlıklarında Arabuluculuk Kanunu'nun noksan ve genel düzenlemeler içermesi sebebiyle hangi uyuşmazlıkların aile arabuluculuğuna elverişli olacağının tespit edilmesi gerekmektedir. Zira Kanun'da gerek genel olarak arabuluculuğa gerekse özel olarak aile arabuluculuğuna elverişli konular tahdidi şeklinde sayılmamıştır. Kanun'un m. 1/II c. 1 düzenlemesi gereğince aile arabuluculuğu yalnızca eşlerin üzerinde tasarrufta bulunabileceği konulara uygulanabilecektir. Ancak bu düzenlemeye göre aile arabuluculuğuna uygun, sınırlı sayıdaki aile hukuku uyuşmazlıklarının neler olduğu konusunda doktrinde fikir birliği bulunmamaktadır. Bu nedenle çalışmamız, Hukuk Uyuşmazlıklarında Arabuluculuk Kanunu çerçevesinde Türk hukukunda aile arabuluculuğunun konusunu, kapsamını ve özellikle boşanma sürecinde aile arabuluculuğunun işlevini değerlendirmeyi amaçlamaktadır.

\section{Anahtar Kelimeler}

Alternatif uyuşmazlı çözüm yöntemleri, Arabuluculuk, Aile arabuluculuğu, Arabuluculuğa elverişlilik, Boşanma 


\section{Einleitung}

Der türkischen Gesellschaft ist die Mediation nicht fremd. Sie ist zwar nicht in der rechtlichen Form, die wir heute verstehen, doch wurden ältere Familienmitglieder als Respektpersonen betrachtet, die auch Konflikte innerhalb der Familie lösten. Die Mediation als juristisches Institut in der Türkei wird insbesondere seit dem Jahr 2006 diskutiert, wo eine wissenschaftliche Kommission für einen Entwurf gegründet wurde ${ }^{1}$. Der Entwurf der Kommission wurde im Jahre 2008 ins Parlament eingereicht, doch wurde die Mediation erst im Jahre 2012 mit dem türkischen Mediationsgesetz in zivilrechtlichen Streitigkeiten mit der Nr. 6325 ( $\operatorname{sog}$. Mediationsgesetz) ins türkische Recht etabliert ${ }^{2}$.

Bei der Mediation als Form der alternativen Streitbeilegung sitzt eine unparteiische Person (Mediator) mit den Konfliktpersonen zusammen und hilft ihnen, eine Konfliktlösung zu finden ${ }^{3}$. Die Hilfe einer unparteiischen Person zur Beilegung der rechtlichen Konflikten in der Familie spielt eine erhebliche Rolle, da die Nerven der Partien oft in solchen Situationen stets sehr angespannt sind. Außerdem leiden nicht nur Ehegatten unter diesen

http://www.adb.adalet.gov.tr/Sayfalar/Teskilat/tarihce.html.

2 Hukuk Uyuşmazlıkların Arabuluculuk Kanunu, Nr. 6325 vom 22.06.2012.

3 Zum Begriff siehe Özbek, Mustafa Serdar: Avukatlık Kanunu'nun 35/A Maddesine Göre Arabuluculuk, Ankara Barosu Dergisi, Heft: 3, 2001, S. 123 f., 129; Ildır, Gülgün: Alternatif Uyuşmazlık Çözümü-Medeni Yargıya Alternatif Yöntemler, Seçkin Yayıncılık, Ankara, 2003, S. 88; Ildır, Gülgün: Alternatif Uyuşmazlık Çözümü ve Hak Arama Özgürlügüü, 75. Yaş Günü için Prof. Dr. Bakı Kuru Armağanı, Türkiye Barolar Birliği Yayınları, Ankara, 2005, S. 386, 392; Tanrıver, Süha: Hukuk Uyuşmazlıkları Bağlamında Alternatif Uyuşmazlık Çözüm Yolları ve Özellikle Arabuluculuk, Türkiye Barolar Birliği Dergisi, Heft: 64, Mai-Juni 2006, S. 165; Yıldırım, M. Kamil: İhtilafların Mahkeme Dışı Usullerle Çözülmesi Hakkında, Prof. Dr. Yavuz Alangoya için Armağan, Beta Yayınları, Istanbul, 2007, S. 340, 347, 349; Bulur, Alper, Alternatif Çözüm Yolları ve Arabuluculuk Yöntemi, Ankara Barosu Dergisi, Jahr: 65, Heft: 4, 2007, S. 31; Kaplan, Yavuz: Arabuluculuk ve Türk Hukuk Uyuşmazlıklarında Arabuluculuk Kanunu Tasarısına Eleştirel Bir Bakış, Milletlerarası Hukuk ve Milletlerarası Özel Hukuk Bülteni, Band: 28, Heft: 1-2, 2008, S. 118; Özmumcu, Seda: Uzak Doğu'da Arabuluculuk Anlayışı ile Türk Hukuk Sisteminde Arabuluculuk Kurumuna Genel Bir Bakış, On Iki Levha Yayıncılık, Istanbul, 2011, S. 273 ff.; Taşpolat Tuğsavul, Melis: Türk Hukukunda Arabuluculuk, Yetkin Yayınları, Ankara, 2012, S. 22, m. w. N. in Fn. 6; Akil, Cenk: Hukuk Uyuşmazlıklarında Arabuluculuk Kanunu'nun Kapsamı, Prof. Dr. Ejder Yılmaz'a Armağan, Band:1, Yetkin Yayınları, Ankara, 2014, S. 75; zur Unparteilichkeit siehe Özbek, Mustafa: Avrupa Konseyi Bakanlar Komitesinin „Aile Arabuluculuğu“ Konulu Tavsiye Kararı, Dokuz Eylül Üniversitesi Hukuk Fakültesi Dergisi, Band: 7, Heft: 2, 2005, S. 89. 
Streitigkeiten, sondern auch deren Kinder, die dadurch negativ beeinflusst werden. Dies, dass auch negative soziale Konsequenzen ausbrechen kann. Dadurch unterscheiden sich diese Konflikte auch von anderen Rechtsgebieten. Zudem haben diese Rechtstreitigkeiten auch soziale Konsequenzen, da die Familie eine große Rolle bei der Erziehung der Kinder spielt ${ }^{4}$. Angesichts der Rolle, die die Familie für die Zukunft der Gesellschaft spielt, wird deutlich, wie wichtig es ist, rechtliche Konflikte innerhalb der Familie einvernehmlich zu lösen. Dementsprechend hat der Staat generell eine Pflicht für das Wohl der Familie und soll man dazu ermutigen, innerhalb der Familie entstandene Konflikte möglichst auf friedfertige Weise zu lösen (siehe Art. 41 Abs. 2 des türk. Grundgesetzes) ${ }^{5}$.

In dieser Untersuchung wird zunächst die Bedeutung der Familienmediation in der Türkei kurz dargestellt. Den Kern dieses Aufsatzes bildet die Bestimmung der familienmediationstauglichen Gegenstände beim Scheidungsprozess nach dem türkischen Mediationsgesetzes.

\section{Einführung in die Familienmediation im türkischen Recht}

\section{a. Zum Begriff der Familienmediation}

Die Familienmediation ist eine außergerichtliche Form der Konfliktlösung, bei der eine unparteiische Person (der Mediator) den Betroffenen eines familienrechtlichen Konflikts zur konstruktiven Konfliktlösung verhilft ${ }^{6}$. Dadurch wird den Betroffenen ermöglicht, die Eltern-Kinder-Beziehung fortzuführen ${ }^{7}$. Zweck der Familienmediation ist es, den Ehegatten bei der Scheidung oder auch bei der Trennung möglichst über

4 Tercan, Erdal: Türk Aile Mahkemeleri, Ankara Üniversitesi Hukuk Fakültesi Dergisi, Band: 5, Heft: 3, Ankara, 2003, S. 19; Akıntürk, Turgut/Ateş, Derya: Aile Hukuku, Band: 2, 22. Aufl., Beta Yayınları, Istanbul, 2020, S. 3-4.

5 Siehe in der Begründung des türk. Gesetzentwurfs über die Einrichtung, die Pflichten und das Verfahren von Familiengerichten https://www.tbmm.gov.tr/tutanaklar/ TUTANAK/TBMM/d22/c002/tbmm22002020ss0015. pdf; Özbek, DEÜHFD 2005, S. 101; Ercan, İbrahim: Boşanma Davalarında Geçerli Olan Yargılama İlkeleri, Süleyman Demirel Üniversitesi Hukuk Fakültesi Dergisi, Band: 4, Heft: 2, 2014, S. 249; Özbek, Mustafa Serdar: Alternatif Uyuşmazlık Çözümü, Band: 2, Yetkin Yayınları, Ankara, 2016, S. 847 ff..

$6 \quad$ Kaplan, S. 118.

7 Siehe in der Empfehlung des Ministerkomitees an die Mitgliedstaaten über Familienmediation, https://www.mikk-ev.de/s-content/uploads/2016/12/Best-practiceguide-DE.pdf; Özbek, DEÜHFD 2005, S. 78 f.; Şıpka, Şükran: Hukuk Uyuşmazlıklarında Arabuluculuk Kanunu Tasarısının Değerlendirilmesi, Istanbul Ticaret Üniversitesi Sosyal Bilimler Dergisi, Jahr: 6, Heft: 12, Herbst 2007 (Sonderheft), S. 173. 
die finanziellen oder elterlichen Folgen zu vermitteln und den Parteien bei der Lösung zu helfen. Die Familienmediation hat auch zum Ziel, die Gerichtskosten zu reduzieren, die für die Konfliktlösung erforderliche Zeit zu verkürzen und die Familiengerichte zu entlasten ${ }^{8}$. Daraus ergibt sich die Aufgabe des Mediators: die Konfliktparteien bei der Bestimmung der Konfliktpunkte und bei der Erarbeitung von Lösungsvorschlägen zu unterstützen ${ }^{9}$.

Insbesondere bei der Erarbeitung von Lösungsvorschlägen übernimmt der Mediator eine aktive Rolle. Meistens leitet der Mediator die Konfliktparteien dazu, eine andere Perspektive des Konflikts einzunehmen und diesen Konflikt konstruktiv zu lösen ${ }^{10}$. Dem Mediator steht jedoch keine Befugnis zu, die Parteien zur Einigung zu zwingen ${ }^{11}$. Ferner dient der Mediator niemals als Richter ${ }^{12}$; er darf über den Konflikt nicht endgültig entscheiden ${ }^{13}$.

Der Mediator ist vielmehr die Person, die für die Konfliktpersonen eine günstige Atmosphäre für die Einigung bereitet ${ }^{14}$. Dies versucht der Mediator

8 Siehe in der Empfehlung des Ministerkomitees an die Mitgliedstaaten über Familienmediation, https://www.mikk-ev.de/s-content/uploads/2016/12/Best-practiceguide-DE.pdf; über die Vorteile der Familienmediation siehe auch Özbek, DEÜHFD 2005, S. 78 f., 102; Ildır, Prof. Dr. Yavuz Alangoya Armağanı, S. 386, 388 ff.; Şıpka, S. 165 f.; über die Vorteile und Nachteile der Mediation im Allgemeinen s. Yıldırım, S. 347 f., 355; Pekcanıtez, Hakan/Atalay, Oğuz/Özekes, Muhammet: Medeni Usul Hukuku, Vedat Kitapç1lı, 6. Aufl., Istanbul, 2018, § 22, S. 608 ff.

9 Bulur, ABD 2007, S. 42 m.w.N.; Kaplan, S. 133.

$10 \quad$ Kaplan, S. 121, 127.

11 Özbek, DEÜHFD 2005, S. 83; Şıpka, S. 165; Özmumcu, S. 278; Pekcanıtez/Atalay/ Özekes, § 22, S. 607.

12 Kaplan, S. 121. Gemäß Art. 15 Abs. 4 des türk. Mediationsgesetzes darf der Mediator die Geschäfte, welche aufgrund ihrer Eigenschaft dem Gericht vorbehalten sind, nicht machen.

13 Özbek, Ankara Barosu Dergisi, S. 123; Tanrıver, Türkiye Barolar Birliği Dergisi, S. 165; Şıpka, S. 166; Yıldırım, S. 340 f., 349; Bulur, ABD 2007, S. 42; Kaplan, S. 118, 121, 145; Akcan, Recep: Hukuk Uyuşmazlıklarında Arabuluculuk Kanunu Tasarısı ile İlgili Bazı Düşünceler, Prof. Dr. Bilge Öztan'a Armağan, Turhan Kitabevi, Ankara, 2008, S. 39; Tanrıver, Süha: Hukuk Uyuşmazlıklarında Arabuluculuk Kanunu Tasarısı'nın Getirdikleri ve Değerlendirilmesi, Makalelerim II (2006-2010), Adalet Yayınları, Ankara, 2011, S. 184; Pekcanıtez/Atalay/Özekes, § 22, S. 607 f. Die Klageerhebung über denselben Konflikt ist vorbehalten, wenn die Parteien sich über den Konflikt nicht einigen konnten. Also schließt die Mediation nicht aus, den Konflikt im Gericht mit Hilfe des Richters zu lösen. Darüber siehe Tanrıver, Türkiye Barolar Birliği Dergisi, S. $151 \mathrm{f}$.

14 Kaplan, S. 121, 126; Tanriver, Makalelerim II, S. 184; Pekcanıtez/Atalay/Özekes, § 22, S. 608. 
durch richtige Fragestellung zu erreichen, ohne dabei in die Wünsche der Konfliktpersonen einzugreifen.

Die Mediation im Scheidungsprozess spielt eine ganz besondere Rolle, weil der Anlass dieser Rechtstreitigkeiten oft mit gemischten Gefühlen, wie z.B. Wut, Gier, Ärger, Eifersucht auftauchen. Das Motiv dieser Konflikte kann dazu führen, dass Ehegatten gegenseitige Ansprüche stellen, über die sie sich kaum einigen können. Hier handelt es sich nicht nur über finanziellen Ansprüchen, oftmals werden auch Kinder in diesen Streit eingezogen. Dies führt zu einer psychischen Belastung der Kinder ${ }^{15}$.

\section{b. Gesetzliche Grundlage}

Die Bedeutung der Familienmediation liegt darin, dass sie das streitige Verhältnis zwischen den Ehegatten vor und nach der Scheidung befriedet, möglichst normalisiert und dadurch erreicht, dass besonders die Kinder diesen Scheidungsprozess mit dem geringsten Schaden überstehen können ${ }^{16}$. Dementsprechend hat der türkische Gesetzgeber mit verschiedenen Gesetzen den Richtern am Familiengericht die Aufgabe zur Schlichtung zwischen den Ehegatten gegeben. Diese Aufgabe ist in Art. 7 Abs. 1 des türk. Gesetzes über die Einrichtung, die Pflichten und das Verfahren von Familiengerichten $(N r .4787)^{17}$, im Art. 137 des türk. Zivilprozessgesetzes $(N r .6100)^{18}$ und im Art. 195 des türk. Zivilgesetzbuches $(Z G B)^{19}$ geregelt worden.

15 Akkaya, Tolga: Boşanma Davasında Alınabilecek Geçici Hukuki Korumalar veya Hakimin Müdahalesi Yoluyla Çocuğun Korunması Kapsamında Zorunlu Arabuluculuk ve Boşanma Süreci (Aile) Danışmanlığı, Ankara Barosu Dergisi, Heft: 2014 /3, S. 31. Akkaya, S. 27 f..; Özbek, Alternatif Uyuşmazlık Çözümü, Band: 2, S. 857 ff.

17 Nach Art. 7 Abs. 1 des türk. Gesetzes über die Einrichtung, die Pflichten und das Verfahren von Familiengerichten fördert das Familiengericht, je nach der Eigenart der zu bearbeitenden Streitigkeiten oder Angelegenheiten, vor Eintritt in die Verhandlung zur Sache, durch Feststellung der Probleme zwischen den Ehegatten bzw. Kindern unter dem Gesichtspunkt des Schutzes der gegenseitigen Zuneigung, des Respekts und der Toleranz eine vergleichsweise Lösung und zieht dazu erforderlichenfalls Fachleute heran. Wird eine solche Einigung nicht erreicht, so wird in der Sache weiter verhandelt. Auch vorbehaltlich anderweitiger gesetzlicher Regelungen kann das Familiengericht nach Art. 6 Abs. 1 Nr. 1,a die Erwachsene zur Erfüllung ihrer ehelichen Pflichten anhalten, erforderlichenfalls auf eine Versöhnung hinwirken. Der Richter kann die Parteien selbst vermitteln oder einen Psychologen, Pädagogen und Sozialarbeiter zur Vermittlung beauftragen (s. Art. 6 Abs. 2). Nach Art. 5 ernennt das Justizministerium bei jedem Gericht je einen Psychologen, Pädagogen und Sozialarbeiter, dabei sind vorzugsweise Personen einzustellen, die verheiratet sind und Kinder haben, das 30. Lebensjahr vollendet haben und auf dem Gebiet von Familienfragen ein postgraduates Studium absolviert haben. Zur Begründung des Entwurfes des Gesetzes über die 
Eine sehr junge Entwicklung im türkischen Recht ist die Inanspruchnahme eines Mediators vor oder nach Erhebung der Scheidungsklage zur Beseitigung oder teilweisen Befriedung der familienrechtlichen Konflikte $^{20}$. Die erste Regelung zur Mediation in

Einrichtung, die Zuständigkeit und das Verfahren der Familiengerichte siehe https://www.tbmm.gov.tr/tutanaklar/TUTANAK/TBMM/d22/c002/tbmm22002020ss00 15.pdf; zur Pflicht des Richters bezüglich der Schlichtung der Parteien nach Art. 7 Abs. 1 des türk. Gesetzes über die Einrichtung, die Pflichten und das Verfahren von Familiengerichten (vgl. ZPO Art. 278 Abs. 1, 2); Ildır, Alternatif Uyuşmazlık Çözümü, S. 147 f.; Tercan, S. 48 f.; Aras, Bahattin: Aile Mahkemelerinde Yargılama Usulü, Ankara Barosu Dergisi, Jahr: 65, Heft: 2, Frühling 2007, S. 159; Yıldırım, S. 344; Tanrıver, Süha: Türk Aile Mahkemesi Hakimlerinin Sulhe Teşvik Ödevi, Makalelerim III, Yetkin Yayınları, Ankara, 2016, S. 199; zur Ansicht, dass der Richter hier als Mediator auftritt, siehe Tanrıver, Türkiye Barolar Birliği Dergisi, S. 173; Taşpolat Tuğsavul, S. 81 f.; darüber, dass „gerichtliche Mediation“ in Art. 7 Abs. 1 des türk. Gesetzes über die Einrichtung, die Pflichten und das Verfahren von Familiengerichten geregelt ist, s. Taşpolat Tuğsavul, S. 82; Özbek, Mustafa Serdar: Alternatif Uyuşmazlık Çözümü, Band: 1, Yetkin Yayınları, Ankara, 2016, S. 638 ff.

Nach Art. 137 des türk. Zivilprozessgesetzes wird eine Vorprüfung vorgesehen, nachdem die Schriften der Parteien untereinander ausgetauscht wurden. Anschließend versucht der Richter, die Parteien nach Möglichkeit zu einem Vergleich zu fördern, wenn es um die Klage, darüber die Parteien frei verfügen dürfen. Darüber siehe http://www.ritsumei.ac.jp/acd/cg/law/lex/rlr30/ghakan.pdf.

19 Nach Art. 195 des türk. ZGB hat der Richter das Recht zum Eingriff in die Ehe, um die Ehe zu schützen. Danach können die Ehegatten gemeinsam oder einzeln das Gericht um Vermittlung anrufen, wenn ein Ehegatte seine Pflichten gegenüber der Familie nicht erfüllt oder die Ehegatten in einer für die eheliche Gemeinschaft wichtigen Angelegenheit uneinig sind (Art. 195 Abs. 1). Das Gericht mahnt die Ehegatten an ihre Pflichten und versucht, sie zu versöhnen; es kann mit ihrem Einverständnis Sachverständige (Psychologen, Pädagogen und Sozialarbeiter, siehe auch Art. 5 des türk. Gesetzes über die Einrichtung, die Pflichten und das Verfahren von Familiengerichten) beiziehen. Wenn nötig, trifft das Gericht auf Begehren eines Ehegatten die vom Gesetz vorgesehenen Maßnahmen (s. auch die in Art. 196-199 erwähnten Maßnahmen). An dieser Stelle versucht der Richter als Schlichter (aber nicht als Mediator) eine gemütliche/angenehme Atmosphäre für die Ehegatten vorzubereiten. Der Richter darf aber die Ehegatten zur Einigung nicht zwingen. Dementsprechend siehe Akil, S. 83; Kaplan, S. 131. Zur Schlichtung der Ehekonflikte kann der Richter auch von Familienberatungsinstitutionen Hilfe holen. Auffällig ist, dass der Richter nach Art. 195 ff. des türk. ZGB in die Ehe eingreifen kann, solange die Ehe weiterbesteht. Anders gesagt, wird hier von den Ehegatten gesprochen, die sich noch nicht scheiden lassen wollen, aber in einer für die eheliche Gemeinschaft wichtigen Angelegenheit uneinig sind und dafür das Gericht um Vermittlung anrufen. Darin liegt der Unterschied zwischen der Familienmediation und die Vermittlung der Ehegatte vom Richter nach Art. 195 des türk. ZGB.

20 Art. 13 Abs. 1 des türk. Mediationsgesetzes; über die Wendung an einen Mediator vor oder nach der Erhebung der Scheidungsklage siehe Özbek, Mustafa: Avukatlık 
familienrechtlichen Konflikten befindet sich im türk. Mediationsgesetz. Nach dem genannten Gesetz wurde die Familienmediation als ,freiwillige“ Mediation geregelt. Jedoch wird deren Anerkennung als verpflichtende Mediation, wie sie für Konflikte i. R. v. Arbeitnehmer-Arbeitgeber Streitigkeiten und das Handelsrecht geregelt ist, kontrovers diskutiert ${ }^{21}$.

\section{c. Die richterliche Prüfung des Vergleichs}

Auffällig ist die Regelung im türkischen Mediationsrecht, wonach das mit Hilfe eines unparteiischen Mediators aufgestellten Mediationsvergleichs seitens der Familiengerichte durch Verhandlung nochmals überprüft werden soll, auch wenn die Parteien sich über alle Punkte geeinigt haben (Art. 18 Abs. 3 Satz 2 des türk. Mediationsgesetzes). Andernfalls wird der Mediationsvergleich ungültig ${ }^{22}$. Der Umfang des richterlichen Untersuchungsrechts beschränkt sich auf die Prüfung der Mediationstauglichkeit und der Vollstreckungsfähigkeit des Vergleichs (Art. 18 Abs. 2 Satz 3 des türk. Mediationsgesetzes; in dieser Richtung Art 21 Abs. 5 der Verordnung über die Mediation, Nr. 30439) ${ }^{23}$. Der türkische

Kanunu'nun 35/A Maddesine Göre Arabuluculuk, Ankara Barosu Dergisi, Heft: 3, 2001, S. 130; Pekcanıtez/Atalay/Özekes, § 22, S. 612, 614.

21 Führt der türkische Gesetzgeber die verpflichtende Mediation für die familienrechtliche Konflikte ein, dann müssten die Ehegatten sich vor der Klageerhebung an die Mediation wenden. Dabei würde die Annahme der verpflichtenden Mediation gleichzeitig zur Aufhebung der Willensfreiheit führen. Dies würde auch eine Abweichung vom „Freiwilligkeitsprinzip“ der Mediation bedeuten. Durch die Anerkennung der verpflichtenden Familienmediation erwerben die Ehegatten die Möglichkeit, über den Konflikt nochmal nachzudenken. Von diesem Standpunkt aus ist die verpflichtende Familienmediation positiv zu betrachten. In dieser Richtung siehe Akkaya, S. 30; zur Verneinung der verpflichtenden Mediation siehe https:/www.istanbulbarosu.org.tr/ HaberDetay.aspx?ID=14275\&Desc=Aile-Hukukunda-Arabuluculuk-Olmaz-; über die Nachteile der verpflichtenden Mediation s. Yıldırım, S. 355.

22 Özbek, Alternatif Uyuşmazlık Çözümü, Band: 2, S. 862.

23 Schaut man in die Praxis, sieht man im nationalen elektronischen Mediationsportal der türkischen Justiz (UYAP für Ulusal Yargl A $\breve{g}_{l}$ Bilişsim Sistemi), dass Rubriken wie, Sorgerecht, Scheidung wegen Untreue, Scheidung wegen unheilbarer Zerrüttung der Ehe, als Mediationsthemen zur Verfügung stehen. Daher denkt man, dass z.B. der Konflikt über das Sorgerecht in Zukunft durch verpflichtende Mediation gelöst wird. Dagegen hat die Fachabteilung für Mediation ausdrücklich erklärt, dass das Sorgerecht nicht mediationstauglich ist. Darüber siehe http://www.adb.adalet.gov.tr/Sayfalar/ soru_gorus_oneriler/index.html. In dieser Richtung siehe in der Lehre Kaplan Güler, Beyhan: Boşanmanın Hukuki Sonuçlarında Arabuluculuk, Sümer Kitabevi, Istanbul, 2014, S. 167 f., 182, 192 f. Darüber, dass Konflikte über das Sorgerecht weniger auftreten, wenn beim Scheidungsprozess die Familienmediation auf Empfehlung des Gerichts anerkannt würde, siehe Akkaya, s. 29. 
Gesetzgeber grenzt daher die Kompetenz der Mediatoren ein und verzichtet nicht auf jegliche staatliche Kontrolle ${ }^{24}$.

\section{d. Vollstreckbarkeit des Mediationsvergleichs}

In Art. 18 Abs. 3 Satz 2 des türk. Mediationsgesetzes wurde ausdrücklich ermöglicht, ein Mediationsvergleich für vollstreckbar erklären zu lassen, indem die Vereinbarung dem Gericht, welches auch im Falle eines gerichtlichen Verfahrens zuständig wäre, vorgelegt und von ihm mit einem entsprechenden Vermerk versehen wird. Mit diesem Vermerk erlangt der Vergleich die Wirkung eines gerichtlichen Urteils (i.S.v Art. 38 des türk. Vollstreckungs- und Insolvenzgesetzes) ${ }^{25}$. Ob der Vermerk erteilt werden kann, wird grundsätzlich nach Aktenlage geprüft. Gemäß Art. 18 Abs. 3 Satz 2 des türk. Mediationsgesetzes muss diese Prüfung beim Vorliegen eines familienrechtlichen Konflikts ausnahmsweise aufgrund einer Gerichtshandlung erfolgen ${ }^{26}$. Bei der Verhandlung wird lediglich die Gegenstände und die Vollstreckbarkeit der Mediationsvereinbarung vom Richter geprüft ${ }^{27}$. Schließlich erklärt der Richter die Mediationsvereinbarung durch einen Vermerk vollstreckbar. Die Bedeutung der Erteilung eines Vermerks liegt darin, dass eine Partei im Falle der Verletzung des Vergleichs der anderen Partei, die Einhaltung des Vergleichs durch eine Klageerhebung erzwingen $\mathrm{kann}^{28}$. Ferner wird die Vollstreckbarkeit des Vergleichs nach Art. 18 Abs. 4 des türk. Mediationsgesetzes trotz des fehlenden Vermerks angenommen, wenn der Vergleich von den Parteien, deren Anwälten und dem Mediator unterschrieben ist.

\section{Gegenstände der Familienmediation}

\section{a. Umfang der Familienmediation}

Im türkischen Mediationsgesetz werden weder die mediationstauglichen noch familienmediationstauglichen Konflikte

\footnotetext{
24 Zur Begründung der staatlichen Kontrolle mit der Qualitätssicherung und dem Schutz des Rechtsverkehrs siehe Yakut, Bahadır: Arabuluculuğun Kanunla Düzenlenmesi Bakımından Amerika Birleşik Devletler Örneği, Türkiye Adalet Akademisi Dergisi, Nisan 2010, Band: 1, Heft: 1, S. 29 ff.; zur Kritik siehe Şıpka, S. 171.

25 Taşpolat Tuğsavul, S. 191 ff. Von der Eigenschaft her ist die Vormerkung zur Vollstreckbarkeit des Vergleichs Gegenstand vom einseitigen Verfahren.

26 http://www.adb.adalet.gov.tr/Sayfalar/soru_gorus_oneriler/index.html.

27 Tanriver, Makalelerim II, S. 205; Pekcanıtez/Atalay/Özekes, § 22, S. 617.

28 Özbek, DEÜHFD 2005, S. 94.
} 
abschließend erwähnt. Anders gesagt, geht aus dem speziellen MediationsGesetz nicht klar hervor, welche Konflikte und Rechtsgebiete für die Mediation geeignet $\operatorname{sind}^{29}$. Es gibt nur die Umfangbestimmung, ohne Konkretisierungen. Daher können lediglich aus den allgemeinen gesetzlichen Regelungen anderer Rechtsgebiete hergeleitet werden, wann ein Gegenstand für die Familienmediation geeignet ist.

Gemäß Art. 1 Abs. 2 des türk. Mediationsgesetzes betrifft dieses Gesetz lediglich die Lösung privatrechtlicher Konflikte ${ }^{30}$, einschließlich solcher mit Auslandsbezug $^{31}$. Diese Konflikte müssen aber aus Rechtsgeschäften entstehen, über die die Parteien frei verfügen dürfen (Art. 1 Abs. 2 Satz 1 des türk. Mediationsgesetzes) ${ }^{32}$. Demnach liegt es nahe, dass Familienmediation dann in Betracht kommt, wenn eine dem Willen der Konfliktparteien unterliegende Angelegenheit vorliegt ${ }^{33}$, d.h. die Lösung des Konflikts durch

29 Zur Ansicht, dass zum Zwecke der Klarstellung die mediationstauglichen Konflikte einzeln im Gesetz zu erwähnen sind, siehe Akcan, S. 43; Kaplan, S. 134, Fn. 51; vgl.

Tanrıver, Makalelerim II, S. 186. Bei der Streitigkeit darüber, ob ein privatrechtlicher Konflikt oder ein Konflikt, über den die Parteien frei verfügen dürfen, vorliegt, darf nicht der Mediator, der Richter entscheiden. In dieser Richtung siehe Akcan, S. 48.

Zur Gesetzesbegründung siehe http://www.kgm.adalet.gov.tr/Tasariasamalari/ Kanunlasan/2012Yili/Kanmetni/6325ss.pdf.

31 Über die Konflikte mit Auslandbezug siehe Kaplan, S. 135 f.; Akil, s. 77 f.

32 In dieser Richtung Özbek, ABD 2001, S. 131; Uyumaz, Alper/Erdoğan, Kemal: Aile Hukukundan Doğan Uyuşmazlıkların Alternatif Çözüm Yolları, Dokuz Eylül Üniversitesi Hukuk Fakültesi Dergisi, Band: 17, Heft: 1, 2015, S. 138; Pekcanıtez/ Atalay/Özekes, $\S 22$, S. 612.

33 Ildır, Alternatif Uyuşmazlık Çözümü, S. 122; Bulur, ABD 2007, S. 32 f.; Taşpolat Tuğsavul, S. 82 f. In Art. 408 des türk. Zivilprozessgesetzes (Nr. 6100) wird geregelt, dass die Streitigkeiten, die sich aus dinglichen Rechten an den unbeweglichen Vermögen oder die Angelegenheiten ergeben, die nicht dem Willen der beiden Parteien unterliegen, für das Schiedsverfahren nicht geeignet sind. Die Regelung mit dem Inhalt, dass die Angelegenheiten, die nicht dem Willen der beiden Parteien unterliegen, für ein alternativen Streitbeilegungsverfahren nicht geeignet ist, gilt auch für die Mediation. Darüber siehe Ildır, Prof. Dr. Baki Kuru Armağanı, S. 390, Fn. 16, 398; Pekcanıtez/ Atalay/Özekes, § 22, S. 612; zur Einzelheiten über das Schiedsverfahren siehe Tanrıver, Süha: Yabancı Mahkeme Kararlarının Türkiye'de Tenfizi Bağlamında Kamu Düzeninin Etkisi, Milletlerarası Hukuk ve Milletlerarası Özel Hukuk Bülteni, Band: 17, Heft: 1-2, 1997, S. 467-492. Gemäß Art. 1 Abs. 4 des Gesetzes über das internationale Schiedsverfahren vom 21.06.2001 ist auf Konflikte, welche den Wünschen der Parteien unterliegen, das Schiedsverfahren anzuwenden. Demgemäß wird in der Lehre vertreten, dass das Schiedsverfahren auch auf die Konflikte in Bezug auf die Ehe zur Anwendung kommt. Darüber siehe Alangoya, H. Yavuz/Yıldırım, M. Kamil/Deren Yıldırım, Nevhis: Medeni Usul Hukuku Esasları, 7. Aufl., Beta Yayınları, Istanbul, 2009, § 43, S. 599. 
einen Vergleich möglich ist ${ }^{34}$. Insbesondere auf Bildung, Aufhebung und Änderung einer Rechtslage gerichtete Gestaltungsklagen, die nicht durch den einseitigen Willen einer Partei erledigt werden können oder eine Einigung der Parteien nicht möglich ist, sondern ein gerichtliches Urteil erfordern, sind von der Mediation ausgeschlossen ${ }^{35}$. Auch in der Lehre wird vertreten, dass diejenigen Konflikte von der Familienmediation ausgenommen sind, die zwingendem Recht unterworfen $\operatorname{sind}^{36}$. Dabei wird behauptet, dass die Angelegenheiten von der Mediation ausgeschlossen sind, welche öffentliche Ordnung betreffen ${ }^{37}$. $\mathrm{Zu}$ berücksichtigen ist aber, dass das türkische Familienrecht in mehreren Hinsichten öffentliche Ordnung betrifft ${ }^{38}$. Dies

34 Dies wird in Art. 313 Abs. 2 des türk. Zivilprozessgesetzes (Nr. 6100) bestätigt. Danach ist der Vergleich lediglich über die Streitigkeiten möglich, über welche die Parteien frei verfügen dürfen. Auch über das Kriterium der Tauglichkeit zum Vergleich siehe die Begründung des Art. 1 des Gesetzentwurfes über das türk. Mediationsgesetz http://www.kgm.adalet.gov.tr/Tasariasamalari/Kanunlasan/2012Yili/Kanmetni/6325ss.p df; Tercan, S. 46 f.; Bulur, ABD 2007, S. 32; Kaplan, S. 133 f.; Taşpolat Tuğsavul, S. 82, 110, 184 ff. m. w. N.; Kaplan Güler, S. 77; Tanrıver, Makalelerim II, S. 186; Koç, Evren: Arabuluculuk Kanunun Uygulanmasına İlişkin Tespitler, Hukuk Uyuşmazlıklarında Arabuluculuk Sempozyumu I, Sümer Kitabevi, Istanbul, 2014, S. 45; Uyumaz/Erdoğan, S. 137; Bulur, Alper: 6325 Sayılı Hukuk Uyuşmazlıklarında Arabuluculuk Kanunu ve uygulaması Hakkında Değerlendirmeler, Prof.Dr. Ramazan Arslan'a Armağan, Band: 1, Yetkin Yayınları, Ankara 2015, S. 499; Özbek, Alternatif Uyuşmazlık Çözümü, Band: 2, S. 1184; Gençcan, Ömer Uğur: Boşanma Usul Hukuku, 2. Aufl., Yetkin Yayınları, Ankara, 2018, S. 836 m.w.N.; zur Behandlung der Mediationstauglichkeit im Rahmen der Regelungen über die Schlichtungstauglichkeit siehe dazu Alangoya, Yavuz/Yıldırım, Kamil/Deren-Yıldırım, Nevhis: Hukuk Muhakemeleri Kanunu Tasarısı, Değerlendirme ve Öneriler, Istanbul Barosu Yayınları, 2006, S. 215; Deren Yıldırım, Nevhis: Uncitral Model Kanunu ve Milletlerarası Tahkim Kanunu Çerçevesinde Milletlerarası Tahkimin Esaslı Sorunları, Alkım Yayınevi, Istanbul, 2004, S. 26 ff.; Akil, S. 81.

35 Ekmekçi, Ömer/Özekes, Muhammet/Atalı, Murat/Seven, Vural: Hukuk Uyuşmazlıklarında Arabuluculuk, 2. Aufl., On Iki Levha Yayıncılık, 2019, S. 50, 52; Taşpolat Tuğsavul, S. 113.

36 Şıpka, S. 174. Nach der Ansicht, die der Mediationsvergleich als einen materiellrechtlichen Vertrag annimmt, unterliegt der Vergleich den Verboten und Beschränkungen von Art. 26 und 27 des türk. OR. Darüber siehe Semizoğlu, Hakan: Hukuk Uyuşmazlıklarında Arabuluculuk Yasa Tasarısı Kapsamında, Tarafların Üzerinde Serbestçe Tasarruf Edebilecekleri İş ve İşlemlerden Doğan Özel Hukuk Uyuşmazlıkları, İstanbul Barosu Dergisi, Band: 82, Heft: 5, 2008, S. 2411 ff.; zu den Einzelheiten über die Eigenschaft des Mediationsvergleichs siehe auch Taşpolat Tuğsavul, S. $103 \mathrm{ff}$.

37 Ekmekçi/Özekes/Atalı/Seven, S. 51 m.w.N.

38 Tercan, S. 19, 47; Demircioğlu, Huriye Reyhan: Aile Hukuku Uyuşmazlıkları Bakımından 6325 sayılı Hukuk Uyuşmazlıklarında Arabuluculuk Kanunu'nun Uygula- 
wird auch dadurch bestätigt, dass die Familie nach Art. 41 Abs. 1 des türk. Verfassungsgesetzes vom 1982 die Grundlage der türkischen Gesellschaft definiert wird ${ }^{39}$. Dies bedeutet aber zugleich, dass über die familienrechtliche Angelegenheiten nicht frei verfügt werden kann ${ }^{40}$.

Darüber hinaus ist ein Mediationsvergleich nach dem Art. 27 des türk. Obligationengesetzes $(O R)$ nichtig, wenn es einen unmöglichen oder widerrechtlichen Inhalt hat oder gegen die Gebotsvorschriften ${ }^{41}$, die Moral oder die öffentliche Ordnung verstößt ${ }^{42}$. Demnach darf die Familienmediationsvereinbarung z.B. dem Kindeswohl nicht widersprechen.

Die Mediation ist bei Rechtstreitigkeiten wegen häuslicher Gewalt ${ }^{43}$ in Art. 1 Abs. 2 des türk. Mediationsgesetzes ausdrücklich geregelt, dass in diesen Fällen die Mediation nicht geeignet ist ${ }^{44}$.

nabilirliği, Türkiye Adalet Akademisi Dergisi, Jahr: 6, Heft: 23, 2015, S. 61; über die Folgen der Scheidung betreffend öffentlicher Ordnung siehe Verfassungsgericht, Urteil v. 15.5.2008, E. 2005/26, K. 2008/105; Verfassungsgericht, Urteil v. 22.1.2016, E. 2014/2-433, K. 2016/63.

39 Demircioğlu, 2015, S. 61,65 ff.

40 Özmumcu, S. 282, Fn. 140. In dieser Hinsicht braucht die „öffentliche Ordnung“ eine Erklärung/Definition. Nach einer Ansicht bedeutet die öffentliche Ordnung die gesamten Regelungen, deren Ziel der Schutz des sozialen, politischen, ökonomischen und moralischen Nutzens der Gesellschaft ist. Darüber siehe Ertekin, Erol/Karataş İzzet, Uygulamada İhtiyari Tahkim ve Yabancı Hakem Kararlarının Tenfizi, Tanınması, Yetkin Yayınları, Ankara, 1997, S. 90. Nach anderer Ansicht ist die öffentliche Ordnung die gesamten Gesetzregelungen, welche das Gesellschaftsinteresse betrifft. Zum Begriff der öffentlichen Ordnung siehe auch Ekmekçi/Özekes/Atalı/Seven, S. 51 m.w.N.; Taşpolat Tuğsavul, S. 109, Fn. 20 m.w.N.; Bulur, Armağan 2015, S. 500. Über die Verhältnis zwischen der öffentlichen Ordnung und der Schiedsbarkeit siehe Tanrıver, MHB 1997, S. 470; Demircioğlu, 2015, S. 60, Fn.70, 71 m.w.N.

41 Über die Gebotsvorschriften im Bereich des Familienrechts s. Demircioğlu, 2015, S. 63 ff.

42 Akil, S. 80

43 Beachte, dass häusliche Gewalt als physische, psychologische, ökonomische und sexuelle Gewalt sich zeigen könnte. Der Grund für den Ausschluss der Mediation bei Rechtstreitigkeiten wegen häuslicher Gewalt ist, dass der Opfer mit dem anderen Ehegatte ein Mediationsverfahren auf gesunde Weise nicht führen könnte. In dem konkreten Fall soll es beantwortet werden, je nachdem ob ein Ehegatte sich wegen häuslicher Gewalt unter Druck fühlt und sich während des Mediationsverfahrens freiwillig entscheidet. Darüber siehe Yıldız, Pervin: Türk Hukukunda Aile Arabuluculuğuna İlişkin Gelişmeler, Ankara Yıldırım Beyazıt Üniversitesi Hukuk Fakültesi Arabuluculuğun Geliştirilmesi Uluslararası Sempozyumu (6-7 Aralık 2018), S. 33-52 m.w.N., https://www.aybu.edu.tr/hukuk/contents/files/ARABULUCULUK\%20 SEMPOZYUM\%20KİTABI.pdf.

Darüber siehe unten S. 13 f. 


\section{b. Einzelne Gegenstände}

\section{1) Scheidung als Mediationsgegenstand}

Gemäß dem türk. ist die Scheidung als Auflösung der Ehe durch die Scheidungsklage definiert. Dazu muss mindestens ein Scheidungsgrund ${ }^{45}$ vorliegen das im Gesetz geregelt ist. Daraus ergibt sich, dass im türkischen Recht die Scheidung lediglich aufgrund der aufgezählten Gründe und eines gerichtlichen Urteils zugelassen wird ${ }^{46}$. Die außergerichtliche Scheidung ist in der Türkei nicht anerkannt ${ }^{47}$.

$\mathrm{Ob}$ die Scheidung für die Mediation geeignet ist, hängt davon ab, ob die oben genannten Kriterien erfüllt sind. Danach ist die Scheidung selbst kein tauglicher Mediationsgegenstand ${ }^{48}$. Die Scheidung ist keine Angelegenheit, die allein dem Willen der Konfliktparteien unterliegt ${ }^{49}$, da sie nur aufgrund

45 Scheidung wegen Ehebruch (Art. 161 des türk. ZGB); Scheidung wegen Lebensnachstellung, sehr schlechtes oder ehrverletzendes Verhalten (Art. 162 des türk. $Z G B)$; Scheidung wegen Begehen von ehrenrührigen Straftat oder unehrenhafte Lebenswandel (Art. 163 des türk. ZGB); Scheidung wegen Verlassens (Art. 164 des türk. $Z G B$ ); Scheidung wegen Geisteskrankheit (Art. 165 des türk. ZGB); Scheidung wegen Zerrüttung; Einverständliche / einvernehmliche Scheidung (Art. 166 Abs. 1 des türk. $Z G B$ ); Scheidung wegen Nicht-Wiederherstellung des Zusammenlebens (Art. 166 Abs. 4 des türk. ZGB).

46 Saymen, Ferit H./Elbir, Halid K.: Türk Medeni Hukuku, Aile Hukuku, Band: 3, Ismail Akgün Matbaas1, Istanbul, 1960, S. 233; Köprülü, Bülent/Kaneti, Selim: Aile Hukuku, Filiz Kitabevi, Istanbul, 1989, S. 144 ff.; Oğuzman, Kemal/Dural, Mustafa: Aile Hukuku, 2. Aufl., Filiz Kitabevi, Istanbul, 1998, S. 112; Zevkliler, Aydın/Ertaş, Şeref/ Havutçu, Ayşe/Acabey, M. Beşir/Gürpınar, Damla: Medeni Hukuk (Temel Bilgiler), 10. Aufl., Turhan Kitabevi, Ankara, 2018, S. 298; Dural, Mustafa/Öğüz, Tufan/Gümüş, Mustafa Alper: Aile Hukuku, Band: 3, Filiz Kitabevi, Istanbul, 2020, Nr. 558; Kılıçoğlu, Ahmet M.: Aile Hukuku, 4. Aufl., Turhan Kitabevi, Ankara, 2019, S. 3; Akıntürk/Ateş, S. 235; Öztan, Bilge: Medeni Hukuk'un Temel Kavramları, Turhan Kitabevi, Ankara, 2019, S. 480.

47 Şanlı, Cemal: Milletlerarası Özel Hukuk, Beta Yayınevi, Istanbul, 2019, S. 144, N. 64; Ürem Çetinel, Merve/Güneş, Biset Sena: Mahkeme Dışı Boşanma Kurumu ve Türk Hukukunun $\mathrm{Bu}$ Kuruma Yaklaşımı, Yıldırım Beyazıt Üniversitesi Hukuk Fakültesi Dergisi, Heft: 1, 2020, S. 309-340.

48 Özbek, Ankara Barosu Dergisi, S. 131; Tercan, S. 47; Taşpolat Tuğsavul, S. 82, 109; Koç, S. 46; Özbek, Alternatif Uyuşmazlık Çözümü, Band: 2, S. 1185; mit der Begründung, dass die Folge "Scheidung“ einen gerichtlichen Urteil braucht, siehe Şıpka, S. 173-174; Akil, S. 82 f.; Bilge, M. Turgay: Hukuk Uyuşmazlıklarında Arabuluculuk Kanunu Açısından Kamu Düzeni Kavramı, Hukuk Uyuşmazlıklarında Arabuluculuk Sempozyumu I, Sümer Kitabevi, Istanbul, 2014, S. 106; Bulur, Armağan 2015, S. 502. 
eines der gesetzlichen Gründe erfolgen kann. Im türkischen Recht berührt die Scheidung, aufgrund der Beendigung einer privatrechtlichen Beziehung, einerseits das Privatrecht, andererseits wirft sie wichtige Folgen bezüglich der öffentlichen Ordnung auf ${ }^{50}$. Daher wurden sowohl die Eheschließung, als auch die Auflösung der Ehe unter bestimmte Voraussetzungen und Formerfordernisse gestellt ${ }^{51}$.

\section{2) Maßnahmen gemäß Art. 169 des türk. ZGB}

Fraglich ist zum Bespiel, ob vorsorgliche Maßnahmen während des Scheidungsverfahrens nach Art. 169 des türk. ZGB mediationstauglich sind. Gemäß Art. 169 des türk. ZGB trifft das Gericht von Amts wegen, prozessuale Maßnahmen soweit die Scheidungs- oder Trennungsklage eingereicht wird. Diese sind für die Dauer des Verfahrens erforderlichen Maßnahmen, wie z.B. die zur Unterbringung und zum Unterhalt des Ehepartners oder der Verwaltung des Vermögens des Ehegatten handelt. Natürlich müssen Maßnahmen zum Wohle des Kindes eingetroffen werden, wie z.B. die Betreuung und der Schutz der gemeinsamen Kinder. Der Unterhalt, die während der Trennung geleistet wird, wird als Trennungsunterhalt bezeichnet. Konflikte über die Anordnung, Änderung oder Aufhebung der genannten Maßnahmen unterliegen nicht der Mediation. Mit Recht wird dies damit begründet, dass diese Maßnahmen das öffentliche Interesse betreffen ${ }^{52}$.

\section{3) Sorgerecht}

Fraglich ist zudem, ob das Sorgerecht oder die Änderung des Sorgerechts des Berechtigten nach der Scheidung mediationstauglich sind ${ }^{53}$.

50 Bezüglich der Folgen betreffend der öffentlichen Ordnung s. Verfassungsgericht, Urteil v. 15.5.2008, E. 2005/26, K. 2008/105; s. auch Tercan, S. 47; Kaplan, S. 134; Taşpolat Tuğsavul, S. 82, $109 \mathrm{ff}$.

51 Über die Verbindung mit der öffentlichen Ordnung siehe Sungurtekin Özkan, Meral: İnşai Karar ve Özellikleri, 75. Yaş Günü için Prof. Dr. Baki Kuru Armağanı, Türkiye Barolar Birliği Yayınları, Ankara, 2004, S. 555; Uyanık Çavuşoğlu, Ayfer: Türk Milletlerarası Özel Hukukunda Boşanma, Beta Basım Yayım, Istanbul, 2006, S. 26.

52 Kaplan Güler, S. 114; Uyumaz/Erdoğan, S. 148 f.; vgl. Bilge, S. 106 f.

53 Beachte aber, dass das Sorgerecht den Eltern gemeinsam zusteht, solange die Ehe weiter besteht (Art. 336 Abs. 1 des türk. ZGB). Nach der Scheidung ist im türkischen Recht kein gemeinsames Sorgerecht der Eltern anerkennt. Die Konflikte der Bestimmung zur Inhaberschaft des Sorgerechts oder der Änderung des Sorgerecht Berechtigten kommen deshalb erst nach der Scheidung vor. 
Unter dem Sorgerecht versteht man die Rechte und Pflichte der Eltern zur Erziehung, Versorgung und Betreuung des minderjährigen Kinds (ausnahmsweise des Entmündigten). Daneben sind die Eltern für das Eigentum ihres Kindes verantwortlich ${ }^{54}$. Anders gesagt, entstehen die „Rechte und Pflichten“ für die Eltern aus dem Sorgerecht ${ }^{55}$. Außerdem umfasst das Sorgerecht den Schutz der Persönlichkeit und des Vermögens des Kinds ${ }^{56}$, sodass das Sorgerecht der Eltern von Amtes wegen entzogen werden kann, wenn die Eltern ihren Pflichten aus dem Sorgerecht nicht nachkommen oder ihr Sorgerecht missbrauchen (Art. 348 ff. des türk. ZGB). Darüber hinaus bedürfen die Vereinbarungen über die Nebenfolgen der Scheidung oder Trennung zur Rechtsgültigkeit der Genehmigung durch den Richter (Art. $184 N r .5$ des türk. ZGB $)^{57}$. Das Sorgerecht untersteht damit staatlicher Kontrolle ${ }^{58}$. Dies ist eine Folge davon, dass der Familie im türkischen Recht und türkischen Gesellschaft große Bedeutung zukommt und beim Sorgerecht neben dem Interesse des Kinds das öffentliche Interesse im Vordergrund steht ${ }^{59}$. Die Regelung von Art. 41 des türk. Grundgesetzes über den Schutz der Familie bestätigt dieses Ergebnis ${ }^{60}$. Folglich hat das Sorgerecht sowohl eine privatrechtliche als auch eine öffentlich-rechtliche Seite im türkischen Recht ${ }^{61}$. Schließlich sind Konflikte

54 Saymen/Elbir, S. 368; Feyzioğlu, Feyzi Necmeddin: Aile Hukuku, 3. Aufl., Filiz Kitabevi, Istanbul, 1986, S. 503 ff.; Köprülü/Kaneti, S. 246; Oğuzman/Dural, S. 272; Dural/Öğüz/Gümüsş, Nr. 1716.

55 Feyzioğlu, S. 503 f.; Hatemi, Hüseyin: Aile Hukuku, 8. Aufl., On Iki Levha Yayıncılık, Istanbul, 2020, Nr. 830; Dural/Öğüz/Gümüş, Nr. 1716; Öztan, S. 520 f.

56 Feyzioğlu, S. 503 ff.; Hatemi, Nr. 836 ff.

57 Akil, S. 83; Öztan, S. 488; Yargitay HGK, E. 1997/2-803, K. 1997/1045, T. 10.12.1997; Yargitay 2. HD, E. 2017/3517, K. 2018/13958, T. 4.12.2018; Yargitay 2. HD, E. 2005/10528, K. 2005/13106, T. 29.9.2005; Yargitay 2. HD, E. 2002/10809, K. 2002/11773, T. 10.10.2002. Zur Ansicht, dass Art. 184 Abs. 1 N. 5 des türk. ZGB mit dem Inhalt, dass die Vereinbarungen über die Folgesachen der Scheidung oder der Trennung zur Rechtsgültigkeit der Genehmigung durch den Richter bedürfen, dem Interesse der Ehegatten und des Kindes dient, siehe. Aras, S. 170.

Pekcanıtez/Atalay/Özekes, § 22, S. 612; Ekmekçi/Özekes/Atalı/Seven, S. 52 f.

$59 \quad$ Kaplan, S. 134; Bilge, S. 106.

60 Art. 41 des türk. Grundgesetzes lautet, "Die Familie ist die Grundlage der türkischen Gesellschaft. Der Staat trifft die notwendigen Massnahmen und gründet die notwendigen Einrichtungen, um das Wohl und Heil der Familie sowie insbesondere den Schutz der Mutter und der Kinder und die Lehre und Anwendung der Familienplannung zu gewaehrleisten.".

61 Yargitay 2. HD, E. 2013/18235, K. 2014/15, T. 13.1.2014. 
über das Sorgerecht nicht mediationstauglich, da gerade kein bloßer privatrechtlicher Konflikt vorliegt ${ }^{62}$.

\section{4) Eltern-Kind-Beziehung}

Ein weiteres Mediationsthema wäre die Gestaltung der persönlichen Beziehung der Eltern zu ihren Kindern nach der Scheidung. Gemäß Art. 182 Abs. 1 des türk. ZGB trifft der Richter über die Ausgestaltung der Elternrechte und der persönlichen Beziehungen der Eltern zu den Kindern bei der Scheidung oder Trennung die nötigen Verfügungen nach Anhörung der Eltern und nötigenfalls der Vormundschaftsbehörde. Ferner wird in Art. 323 des türk. ZGB geregelt, dass der Elternteil, der die elterliche Sorge oder Obhut nicht erhalten hat, Anspruch auf angemessenen persönlichen Umgang mit den Kindern zu haben. Zudem wird in Art. 41 Abs. 2 des türk. Grundgesetzes vorgesehen, dass jedes Kind das Recht auf Schutz und Fürsorge sowie vorbehaltlich offensichtlich höherer Interessen des Kindes auf Begründung und Unterhaltung einer persönlichen und direkten Beziehung zur Mutter und zum Vater hat. $\mathrm{Zu}$ beachten ist aber, dass die Gestaltung der persönlichen Beziehungen der Eltern zu den Kindern nach der Scheidung die Aufgabe und Befugnis des Richters ist (Art. 182 des türk. $Z G B)$. Deshalb können die persönlichen Beziehungen der Eltern zu den Kindern nach der Scheidung nicht durch die Mediation ausgestaltet werden $^{63}$.

\section{5) Güterrechtliche Wirkungen}

Kommt es zum Streit zwischen den Geschiedenen über güterrechtliche Folgen, hat dieser Streit in der Regel eine wirtschaftliche Dimension, etwa bei Ansprüchen auf Ausgleich des Güterstands (wie Eigenanteilansprüche, Werterhöhungsanprüche). $\mathrm{Da}$ die Ausgleichsansprüche infolge der Beendigung des Güterstands rein wirtschaftliche Aspekte betreffen und daher der uneingeschränkten Disposition der Geschiedenen unterliegen,

62 Dementsprechend siehe Tercan, S. 47; zur Mediationstauglichkeit der Bestimmung des Sorgerecht-Berechtigten und der Beziehung des Kindes zum Ehegatten, welchem das Sorgerecht nicht zusteht, siehe Özbek, Alternatif Uyuşmazlık Çözümü, Band: 2 , S. 862.

Bilge, S. 106; Kaplan Güler, S. 166 ff., 182, 192 f.; Akil, S. 83 f.; Uyumaz/Erdoğan, s. 157; hinsichtlich des Kindergelds siehe Uyumaz/Erdoğan, s. 155 ff.; zur Mediationstauglichkeit der Gestaltung der persönlichen Beziehungen der Eltern zu den Kindern siehe Bulur, Armağan 2015, S. 502. 
können diese Ausgleichsansprüche Gegenstand einer Familienmediation $\operatorname{sein}^{64}$.

\section{6) Häusliche Gewalt}

Auch bei häuslicher Gewalt stellt sich die Frage nach der Zulässigkeit einer Familienmediation. In Art. 1 Abs. 2 des türk. Mediationsgesetzes wird ausdrücklich geregelt, dass die Konflikte über häusliche Gewalt nicht mediationstauglich $\operatorname{sind}^{65}$. Danach wird die Familienmediation für einen Konflikt unzulässig erklärt, welcher nur aus häuslicher Gewalt entstanden ist. Beispielsweise liegen die Schadenersatzansprüche aus Gewalttaten des Ehegatten außerhalb des Anwendungsbereichs der Familienmediation. Zugelassen ist andererseits die Familienmediation für Konflikte mit wirtschaftlichem Bezug, wie z.B. die Schadenersatzansprüche, über die die

64 Taşpolat Tuğsavul, S. 110, 113; vgl. Bulur, Armağan 2015, S. 501; Özbek, ABD 2001, S. 131; Başözen, Ahmet: Hukuk Uyuşmazlıklarında Arabuluculuk Kanunu Tasarısı Taslağı'na Dair Değerlendirme, Erciyes Üniversitesi Hukuk Fakültesi Dergisi, Band: 2, Heft: 1-2, 2007, S. 235-239; Uyumaz/Erdoğan, s. 151 ff.; Özbek, Alternatif Uyuşmazlık Çözümü, Band: 2, S. 862 und S. 1186, Fn. 29; Demircioğlu, Huriye Reyhan: 6325 Sayılı Kanun'un Aile Hukuku Uyuşmazlıklarında Uygulanabilirliği, Ankara Yıldırım Beyazıt Üniversitesi Hukuk Fakültesi Arabuluculuğun Geliştirilmesi Uluslararas1 Sempozyumu (6-7 Aralık 2018), S. 64, https://www.aybu.edu.tr/hukuk/ contents/files/ARABULUCULUK\%20SEMPOZYUM\%20KITABI.pdf; zur Mediationstauglichkeit des Schadenersatzes und Schmerzgeldes siehe Kaplan Güler, S. 123 ff., 127 ff.; Bilge, S. 104; zur Mediatonstauglichkeit der Konflikte über die Bedürftigkeitsrente nach Art. 175 des türk. ZGB siehe Şipka, S. 174; Kaplan Güler, S. 140 f.; Bilge, S. 104. Darüber, dass die Ansprüche aus dem Ausgleich des Güterstands für die Mediation nicht geeignet sind, siehe Uyumaz/Erdoğan, s. $154 \mathrm{f}$.

Art. 48 des Übereinkommens des Europarats zur Verhütung und Bekämpfung von Gewalt gegen Frauen und häuslicher Gewalt von 2011 (sog. Istanbul-Konvention) sieht das Verbot verpflichtender alternativer Streitbeilegungsverfahren bei Konflikten mit der Behauptung häuslicher Gewalt vor. Dies ist auch so zu interpretieren, dass bei Konflikten mit der Behauptung häuslicher Gewalt freiwillige Mediation nach dem Übereinkommen nicht verboten ist.

Über das Verbot verpflichtender alternativer Streitbeilegungsverfahren für die Konflikten in Bezug auf Gewalt gegen Frauen siehe auch Art. 48 Abs. 1 der IstanbulKonvention: „Die Vertragsparteien treffen die erforderlichen gesetzgeberischen oder sonstigen Maßnahmen, um verpflichtende alternative Streitbeilegungsverfahren, einschließlich Mediation und Schlichtung, wegen aller in den Geltungsbereich dieses Übereinkommens fallenden Formen von Gewalt zu verbieten.". Zur Ablehnung der Mediation bei häuslicher Gewalt aufgrund öffentlichen Interesses s. Pekcanıtez/Atalay/ Özekes, § 22, S. 612. Zu Beachte ist auch, dass die Konflikte über häusliche Gewalt durch einen gerichtlichen Urteil zu lösen sind und daher von der Mediation ausgeschlossen sind. Darüber s. Ekmekçi/Özekes/Atalı/Seven, S. 53. 
Konfliktparteien frei verfügen dürfen ${ }^{66}$. Im Rahmen der Scheidung könnte der Fall sein, dass eine Scheidungsklage wegen häuslicher Gewalt bereits erhoben wurde und es um die finanzielle Folgen der Scheidung geht ${ }^{67}$.

Der Ausschluss der Konflikte über häusliche Gewalt aus der Mediation wird von der Justizkommission damit begründet, dass die Parteien bei den Verhandlungen während der Mediation frei von Druck und Angst sein sollen. Die Mediation muss in einer Atmosphäre geschehen, in der beide Parteien sich sicher fühlen. Untersuchungen legen dar, dass die Parteien sich unsicher fühlen, wenn häusliche Gewalt vorliegt oder eine Partei der anderen droht. Infolgedessen sind die Konflikte anlässlich häuslicher Gewalt nicht mediationstauglich ${ }^{68}$.

Daher wird vertreten, dass die Konflikte in Bezug auf häusliche Gewalt und die Konflikte in Bezug auf Gewalt gegen Frauen voneinander unterschieden werden müssen, bevor die Mediationstauglichkeit festgestellt wird $^{69}$.

Beachtlich ist, dass häusliche Gewalt als physische, psychologische, verbale ökonomische, soziale und sexuelle Gewalt sich zeigen könnte. Wie oben erwähnt, ist der Grund für den Ausschluss der Mediation bei Rechtstreitigkeiten wegen häuslicher Gewalt, dass der Opfer mit dem anderen Ehegatte ein Mediationsverfahren auf gesunde Weise nicht führen könnte. Im konkreten Fall soll es beantwortet werden, je nachdem ob ein Ehegatte sich wegen häuslicher Gewalt unter Druck fühlt und sich während des Mediationsverfahrens freiwillig entscheidet ${ }^{70}$.

66 Özbek, ABD 2001, S. 131; Özbek, Alternatif Uyuşmazlık Çözümü, Band: 2, S. 1186; Demircioğlu, 2015, S. 71 ff.

67 Zur Einzelheiten und und zum Streit darüber siehe Demircioğlu, 2015, S. 71 ff.; Demircioğlu, 2018, S. 55.

68 http://www.kgm.adalet.gov.tr/Tasariasamalari/Kanunlasan/2012Yili/Kanmetni/ 6325ss.pdf; siehe auch Art. 48 der Istanbul-Konvention, https://rm.coe.int/1680462545.

69 Über ausführliche Informationen siehe Börü, Levent: Kadına Karşı Şiddette Arabuluculuk Kurumuna İlişkin Bazı Değerlendirmeler, Türkiye Barolar Birliği Dergisi 2017 (Sonderheft), S. $173 \mathrm{ff}$.

70 Darüber siehe Yıldız, Pervin: Türk Hukukunda Aile Arabuluculuğuna İlişkin Gelişmeler, Ankara Yıldırım Beyazıt Üniversitesi Hukuk Fakültesi Arabuluculuğun Geliştirilmesi Uluslararası Sempozyumu (6-7 Aralık 2018), S. 33-52 m.w.N., https://www.aybu.edu.tr/hukuk/contents/files/ARABULUCULUK\%20SEMPOZYUM \%20KITABI.pdf. Darüber, dass die Familienmediation über familienrechtliche Konflikte unmöglich ist, siehe die Ansicht von Frauenrechtszentrum der Anwaltskammer Istanbul https://www.istanbulbarosu.org.tr/HaberDetay.aspx?ID= 14275\&Desc=Aile-Hukukunda-Arabuluculuk-Olmaz-. 
Es gibt aber auch Gründe, die an einem generellen Ausschluss der Konflikte anlässlich häuslicher Gewalt aus dem Anwendungsbereich der Familienmediation zweifeln lässt. So kann es beispielsweise durchaus auch im Interesse aller Parteien, gerade auch des Opfers, sein, den Konflikt möglichst schnell lösen zu wollen. Ein Konflikt kann aber gerade im Rahmen einer Familienmediation schneller zu einem Ende gebracht, werden als in einem Gerichtsverfahren.

\section{Gesetzänderungsvorschlag}

Nach Art. 7 Abs. 1 des türk. Gesetzes über die Einrichtung, die Pflichten und das Verfahren von Familiengerichten fordert das Familiengericht, je nach der Eigenart der zu bearbeitenden Streitigkeiten oder Angelegenheiten, vor Eintritt in die Verhandlung zur Sache, durch Feststellung der Probleme zwischen den Ehegatten bzw. Kindern unter dem Gesichtspunkt des Schutzes der gegenseitigen Zuneigung, des Respekts und der Toleranz eine vergleichsweise Lösung und zieht dazu erforderlichenfalls Fachleute heran. Wird eine solche Einigung nicht erreicht, so wird in der Sache weiter verhandelt ${ }^{71}$.

Es bräuchte wichtiger Gesetzesänderungen des türk. ZGB, wenn anerkannt werden würde, dass die Ehe allein durch das Mediationsverfahren, ohne Beteiligung des Richters aufgelöst werden könnte. Für diesen Fall wäre ein Vorschlag zur Änderung des Art. 7 des Gesetzes über die Einrichtung, die Zuständigkeit und das Verfahren der Familiengerichte: "Das Familiengericht strebt, je nach Eigenart der zu verhandelnden Streitigkeiten oder Angelegenheiten, vor Beginn der Verhandlung zur Sache, durch Feststellung der Probleme zwischen Ehegatten bzw. Kindern und unter den Gesichtspunkten des Schutzes der gegenseitigen Zuneigung, des Respekts und der Toleranz, eine Lösung in Form eines Vergleichs oder Mediation an. Hierfür zieht es erforderlichenfalls Fachleute heran. Wird eine solche Einigung nicht erreicht, so wird in der Sache erhandelt ${ }^{672}$. Dies bedeutet aber, auf gerichtliche Kontrolle zu beharren. Danach soll Art. 184 Abs. 1 Nr. 5 des türk. ZGB so geändert werden: „Die Vereinbarungen über die Folgesachen der Scheidung oder der Trennung zur Rechtsgültigkeit bedürfen der Genehmigung durch den Richter, auch wenn sie durch die Mediation abgeschlossen wurde". Gemäß der Gesetzesänderung mit diesem Inhalt bedürfe es eine weitere Regelung über die Vollstreckbarkeit des

71 http://www.tuerkei-recht.de/downloads/famgg.pdf.

72 Zur Übersetzung siehe http://www.tuerkei-recht.de/downloads/famgg.pdf. 
Vergleichs nicht. Nach den geplanten Änderungen in der Türkei muss der Vergleich, das mit Hilfe des Mediators abgeschlossen wird, vom Richter überprüft werden ${ }^{73}$.

\section{Ergebnis}

Hintergrund der Verbreitung der Mediation in der Türkei ist die türkische Konfliktkultur. Die „Mediation“ ist ein Teil des türkischen Gesellschaftslebens. Die Anerkennung der Möglichkeit zur einvernehmlichen und schnellen Lösung familienrechtlicher Konflikte durch einen unparteiischen und fachkundigen Dritten im türkischen Recht ist jedoch ein neues und aktuelles Thema.

Wegen der unvollständigen und rudimentären Regelung der Familienmediation im türkischen Mediationsgesetz bedarf es der Bestimmung der mediationstauglichen Gegenstände. Ob ein Konflikt vom Anwendungsbereich der Familienmediation erfasst ist, lässt sich zusammenfassend anhand folgender Kriterien bestimmen: Die Konflikte sind

- privatrechtlich (können Auslandsbezug haben),

- unterliegen der Disposition der Parteien,

- sind nicht dem zwingenden Recht unterworfen,

- betreffen nicht die öffentliche Ordnung.

Danach sind nur die Ausgleichsansprüche infolge der Beendigung des Güterstands die Gegenstände der Familienmediation anlässlich der Scheidung im türkischen Recht. Demgegenüber sollten die Scheidung selbst; Konflikte über die Anordnung, Änderung oder Aufhebung der genannten Maßnahmen gemäß Art. 169 des türk. ZGB; die Konflikte über das Sorgerecht; die Gestaltung der persönlichen Beziehungen der Eltern zu den Kindern nach der Scheidung; Konflikte in Bezug auf häusliche Gewalt aus der Familienmediation ausgenommen werden.

73 Zum Gesetzesänderungsvorschlag siehe der Bericht von Türkiye'de Hukuk Uyuşmazlıklarında Arabuluculuk Uygulamalarının Geliştirilmesi Aile Arabuluculuğu Mevzuat Çalıştayı III (unveröffentlich, privat mitgeteilt per Email von Prof.Dr. Şükran Şıpka), zum Workshop s. https://www.coe.int/tr/web/ankara/-/3rd-workshop-on-familymediation. Hiermit bedanke ich mich bei geehrter Prof.Dr. Şükran Şıpka für ihre akademische Hilfe. 


\section{LITERATURVERZEICHNIS}

Akcan, Recep: Hukuk Uyuşmazlıklarında Arabuluculuk Kanunu Tasarısı ile İlgili Bazı Düşünceler, Prof. Dr. Bilge Öztan'a Armağan, Turhan Kitabevi, Ankara, 2008, S. 39-51.

Akıntürk, Turgut/Ateş, Derya: Aile Hukuku, Band: 2, 22. Aufl., Beta Yayınları, Istanbul, 2020.

Akil, Cenk: Hukuk Uyuşmazlıklarında Arabuluculuk Kanunu'nun Kapsamı, Prof. Dr. Ejder Yılmaz'a Armağan, Band:1, Yetkin Yayınları, Ankara, 2014, S. 75-137.

Akkaya, Tolga: Boşanma Davasında Alınabilecek Geçici Hukuki Korumalar veya Hakimin Müdahalesi Yoluyla Çocuğun Korunması Kapsamında Zorunlu Arabuluculuk ve Boşanma Süreci (Aile) Danışmanlığı, Ankara Barosu Dergisi, Heft: 2014 /3, S. 23-62.

Alangoya, H. Yavuz/Yıldırım, M. Kamil/Deren Yıldırım, Nevhis: Medeni Usul Hukuku Esasları, 7. Aufl., Beta Yayınları, Istanbul, 2009.

Alangoya, Yavuz/Yıldırım, Kamil/Deren-Yıldırım, Nevhis: Hukuk Muhakemeleri Kanunu Tasarısı, Değerlendirme ve Öneriler, Istanbul Barosu Yayınları, 2006.

Aras, Bahattin: Aile Mahkemelerinde Yargilama Usulü, Ankara Barosu Dergisi, Jahr: 65, Heft: 2, Frühling 2007, S. 158-178.

Başözen, Ahmet: Hukuk Uyuşmazlıklarında Arabuluculuk Kanunu Tasarısı Taslağı'na Dair Değerlendirme, Erciyes Üniversitesi Hukuk Fakültesi Dergisi, Band: 2, Heft: 1-2, 2007, S. 235-239.

Bilge, M. Turgay: Hukuk Uyuşmazlıklarında Arabuluculuk Kanunu Açısından Kamu Düzeni Kavramı, Hukuk Uyuşmazlıklarında Arabuluculuk Sempozyumu I, Sümer Kitabevi, Istanbul, 2014, S. 93-114.

Börü, Levent: Kadına Karşı Şiddette Arabuluculuk Kurumuna İlişkin Bazı Değerlendirmeler, Türkiye Barolar Birliği Dergisi 2017 (Sonderheft), S. 173-198.

Bulur, Alper: Alternatif Çözüm Yolları ve Arabuluculuk Yöntemi, Ankara Barosu Dergisi, Jahr: 65, Heft: 4, 2007, S. 30-46.

Bulur, Alper: 6325 Sayılı Hukuk Uyuşmazlıklarında Arabuluculuk Kanunu ve uygulaması Hakkında Değerlendirmeler, Prof.Dr. Ramazan Arslan'a Armağan, Band: 1, Yetkin Yayınları, Ankara, 2015, S. 499-514.

Demircioğlu, Huriye Reyhan: Aile Hukuku Uyuşmazlıkları Bakımından 6325 sayılı Hukuk Uyuşmazlıklarında Arabuluculuk Kanunu'nun Uygulanabilirliği, Türkiye Adalet Akademisi Dergisi, Jahr: 6, Heft: 23, 2015, S. 45-84. 
Demircioğlu, Huriye Reyhan: 6325 Sayılı Kanun'un Aile Hukuku Uyuşmazlıklarında Uygulanabilirliği, Ankara Yıldırım Beyazıt Üniversitesi Hukuk Fakültesi Arabuluculuğun Geliştirilmesi Uluslararası Sempozyumu (6-7 Aralik 2018), S. 53-56, https://www.aybu.edu.tr/ hukuk/contents/files/ARABULUCULUK\%20SEMPOZYUM\%20KİT ABI.pdf.

Deren Yıldırım, Nevhis: Uncitral Model Kanunu ve Milletlerarası Tahkim Kanunu Çerçevesinde Milletlerarası Tahkimin Esaslı Sorunları, Alkım Yayınevi, Istanbul, 2004.

Dural, Mustafa/Öğüz, Tufan/Gümüş, Mustafa Alper: Aile Hukuku, Band: 3, Filiz Kitabevi, Istanbul, 2020.

Ekmekçi, Ömer/Özekes, Muhammet/Atalı, Murat/Seven, Vural: Hukuk Uyuşmazlıklarında Arabuluculuk, 2. Aufl., On Iki Levha Yayıncılık, 2019.

Ercan, İbrahim: Boşanma Davalarında Geçerli Olan Yargılama İlkeleri, Süleyman Demirel Üniversitesi Hukuk Fakültesi Dergisi, Band: 4, Heft: 2, 2014, S. 249-269.

Ertekin, Erol/Karataş, İzzet: Uygulamada İhtiyari Tahkim ve Yabanc1 Hakem Kararlarının Tenfizi, Tanınması, Yetkin Yayınları, Ankara, 1997.

Feyzioğlu, Feyzi Necmeddin: Aile Hukuku, 3. Aufl., Filiz Kitabevi, Istanbul, 1986.

Gençcan, Ömer Uğur: Boşanma Usul Hukuku, 2. Aufl., Yetkin Yayınları, Ankara, 2018.

Hatemi, Hüseyin: Aile Hukuku, 8. Aufl., On Iki Levha Yayıncılık, Istanbul, 2020.

Ildır, Gülgün: Alternatif Uyuşmazlık Çözümü ve Hak Arama Özgürlüğü, 75. Yaş Günü için Prof. Dr. Baki Kuru Armağanı, Türkiye Barolar Birliği Yayınları, Ankara, 2005, S. 385-399.

Ildır, Gülgün: Alternatif Uyuşmazlık Çözümü-Medeni Yargıya Alternatif Yöntemler, Seçkin Yayıncılık, Ankara, 2003.

Kaplan, Yavuz: Arabuluculuk ve Türk Hukuk Uyuşmazlıklarında Arabuluculuk Kanunu Tasarısına Eleştirel Bir Bakış, Milletlerarası Hukuk ve Milletlerarası Özel Hukuk Bülteni, Band: 28, Heft: 1-2, 2008, S. 115146.

Kaplan Güler, Beyhan: Boşanmanın Hukuki Sonuçlarında Arabuluculuk, Sümer Kitabevi, Istanbul, 2014. 
Kılıçoğlu, Ahmet M.: Aile Hukuku, 4. Aufl., Turhan Kitabevi, Ankara, 2019.

Koç, Evren: Arabuluculuk Kanunun Uygulanmasına İlişkin Tespitler, Hukuk Uyuşmazlıklarında Arabuluculuk Sempozyumu I, Sümer Kitabevi, Istanbul, 2014, S. 43-51.

Köprülü, Bülent/Kaneti, Selim: Aile Hukuku, Filiz Kitabevi, Istanbul, 1989.

Oğuzman, Kemal/Dural, Mustafa: Aile Hukuku, 2. Aufl., Filiz Kitabevi, Istanbul, 1998.

Özbek, Mustafa Serdar: Alternatif Uyuşmazlık Çözümü, Band: 1, Yetkin Yayınları, Ankara, 2016.

Özbek, Mustafa Serdar: Alternatif Uyuşmazlık Çözümü, Band: 2, Yetkin Yayınları, Ankara, 2016.

Özbek, Mustafa Serdar: Avukatlik Kanunu'nun 35/A Maddesine Göre Arabuluculuk, Ankara Barosu Dergisi, Heft: 3, 2001, S. 113-139.

Özbek, Mustafa: Avrupa Konseyi Bakanlar Komitesinin "Aile Arabuluculuğu” Konulu Tavsiye Kararı, Dokuz Eylül Üniversitesi Hukuk Fakültesi Dergisi, Band: 7, Heft: 2, 2005, S. 71-102.

Özmumcu, Seda: Uzak Doğu'da Arabuluculuk Anlayışı ile Türk Hukuk Sisteminde Arabuluculuk Kurumuna Genel Bir Bakış, On Iki Levha Yayıncılik, Istanbul, 2011.

Öztan, Bilge: Medeni Hukuk'un Temel Kavramları, Turhan Kitabevi, Ankara, 2019.

Pekcanıtez, Hakan/Atalay, Oğuz/Özekes, Muhammet: Medeni Usul Hukuku, Vedat Kitapçılık, 6. Aufl., Istanbul, 2018.

Saymen, Ferit H./Elbir, Halid K.: Türk Medeni Hukuku, Aile Hukuku, Band: 3, Ismail Akgün Matbaas1, Istanbul, 1960.

Semizoğlu, Hakan: Hukuk Uyuşmazlıklarında Arabuluculuk Yasa Tasarısı Kapsamında, Tarafların Üzerinde Serbestçe Tasarruf Edebilecekleri İş ve İşlemlerden Doğan Özel Hukuk Uyuşmazlıkları, Istanbul Barosu Dergisi, Band: 82, Heft: 5, 2008, S. 2411-2415.

Sungurtekin Özkan, Meral: İnşai Karar ve Özellikleri, 75. Yaş Günü için Prof. Dr. Baki Kuru Armağanı, Türkiye Barolar Birliği Yayınları, Ankara, 2004, S. 553-576.

Şanlı, Cemal: Milletlerarası Özel Hukuk, Beta Yayınevi, Istanbul, 2019.

Şıpka, Şükran: Hukuk Uyuşmazlıklarında Arabuluculuk Kanunu Tasarısının Değerlendirilmesi, Istanbul Ticaret Üniversitesi Sosyal Bilimler Dergisi, Jahr: 6, Heft: 12, Herbst 2007 (Sonderheft), S. 163-175. 
Tanrıver, Süha: Hukuk Uyuşmazlıkları Bağlamında Alternatif Uyuşmazlık Çözüm Yolları ve Özellikle Arabuluculuk, Türkiye Barolar Birliği Dergisi, Heft: 64, Mai-Juni 2006, S. 151-177.

Tanrıver, Süha: Hukuk Uyuşmazlıklarında Arabuluculuk Kanunu Tasarısı'nın Getirdikleri ve Değerlendirilmesi, Makalelerim II (20062010), Adalet Yayınları, Ankara, 2011, S. 183-211.

Tanrıver, Süha: Türk Aile Mahkemesi Hakimlerinin Sulhe Teşvik Ödevi, Makalelerim III, Yetkin Yayınları, Ankara, 2016, S. 199-203.

Tanrıver, Süha: Yabancı Mahkeme Kararlarının Türkiye'de Tenfizi Bağlamında Kamu Düzeninin Etkisi, Milletlerarası Hukuk ve Milletleraras1 Özel Hukuk Bülteni, Band: 17, Heft: 1-2, 1997, S. 467-492.

Taşpolat Tuğsavul, Melis, Türk Hukukunda Arabuluculuk, Yetkin Yayınları, Ankara, 2012.

Tercan, Erdal: Türk Aile Mahkemeleri, Ankara Üniversitesi Hukuk Fakültesi Dergisi, Band: 5, Heft: 3, Ankara, 2003, S. 19-54.

Uyanık Çavuşoğlu, Ayfer: Türk Milletlerarası Özel Hukukunda Boşanma, Beta Basım Yayım, Istanbul, 2006.

Uyumaz, Alper/Erdoğan, Kemal: Aile Hukukundan Doğan Uyuşmazlıkların Alternatif Çözüm Yolları, Dokuz Eylül Üniversitesi Hukuk Fakültesi Dergisi, Band: 17, Heft: 1, 2015, S. 119-169.

Ürem Çetinel, Merve/Güneş, Biset Sena: Mahkeme Dışı Boşanma Kurumu ve Türk Hukukunun $\mathrm{Bu}$ Kuruma Yaklaşımı, Yıldırım Beyazıt Üniversitesi Hukuk Fakültesi Dergisi, Heft: 1, 2020, S. 309-340.

Yakut, Bahadır: Arabuluculuğun Kanunla Düzenlenmesi Bakımından Amerika Birleşik Devletler Örneği, Türkiye Adalet Akademisi Dergisi, Nisan 2010, Band: 1, Heft: 1, S. 29-80.

Yıldırım, M. Kamil: İhtilafların Mahkeme Dışı Usullerle Çözülmesi Hakkında, Prof. Dr. Yavuz Alangoya için Armağan, Beta Yayınları, Istanbul, 2007, S. 337-360.

Yıldız, Pervin: Türk Hukukunda Aile Arabuluculuğuna İlişkin Gelişmeler, Ankara Yıldırım Beyazıt Üniversitesi Hukuk Fakültesi Arabuluculuğun Geliştirilmesi Uluslararası Sempozyumu (6-7 Aralık 2018), S. 33-52, https://www.aybu.edu.tr/hukuk/contents/files/ARABULUCULUK\%20 SEMPOZYUM\%20KİTABI.pdf.

Zevkliler, Aydın/Ertaş, Şeref/Havutçu, Ayşe/Acabey, M. Beşir/Gürpınar, Damla: Medeni Hukuk (Temel Bilgiler), 10. Aufl., Turhan Kitabevi, Ankara, 2018. 